Journal of Applied Pharmaceutical Science Vol. 2 (9), pp. 075-082, September, 2012

Available online at http://www.japsonline.com

DOI: $10.7324 /$ JAPS.2012.2916

ISSN 2231-3354 (cc) BY-NC-SA

\title{
In Vitro Antimicrobial and Antioxidant Adivity of Chitosan Isolated from Podophthalmus Vigil
}

\author{
K. Prabu* and E. Natarajan \\ Centre of Advanced Study in Marine Biology, Annamalai University, Parangipettai - 608 502, India.
}

\section{ARTICLE INFO}

Article history:

Received on: 30/08/2012

Revised on: 09/09/2012

Accepted on: 15/09/2012

Available online: 28/09/2012

Key words:

Antimicrobial,

Antioxidant,

Podophthalmus vigil,

Agar-disc diffusion,

Chitin, Chitosan,

\begin{abstract}
In the present study, Chitin has been extracted from Podophthalmus vigil. The obtained chitin was transformed into the more useful chitosan we evaluated the antimicrobial activity of different concentrations $(25 \%, 50 \%, 75 \%$ and $100 \%)$ of chitosan against 10 species of bacteria and fungi by agar-disc diffusion method. As the concentration of chitosan increased, the antimicrobial effect was strengthened. In the conjugated diene method, the total antioxidant activity of chitosan was ranging from $18.37 \%$ to $79.58 \%$ at varying concentrations $(0.1$ to $10 \mathrm{mg} / \mathrm{ml})$. The reducing capability ranged from of $0.12 \%$ to $0.48 \%$ at varying concentration $(0.1$ to $10 \mathrm{mg} / \mathrm{ml})$. The 1, 1-diphenyl-2-picrylhydrazyl (DPPH) radical scavenging potential of chitosan ranged from $18.08 \%$ to $55.56 \%$ at varying concentrations $(0.1$ to $10 \mathrm{mg} / \mathrm{ml})$. The chelating ability of chitosan from Podophthalmus vigil on ferrous ions was ranging from $25.82 \%$ to $73.54 \%$ for the concentration between $0.1-10 \mathrm{mg} / \mathrm{ml}$. Hydroxyl radicals scavenging activity of chitosan $(0.125-2 \mathrm{mg} / \mathrm{ml}) \mathrm{was}$ found to be higher than the ascorbic acid and the range was from $23.18 \%$ to $93.28 \%$. Superoxide anion radical was ranging from $5.21 \%$ to $65.81 \%$ for the concentration between $0.125-2 \mathrm{mg} / \mathrm{ml}$. overall, chitosan from Podophthalmus vigil was good in antimicrobial and antioxidant activity, and may be used as a source of antioxidants, as a possible food supplement or ingredient in the pharmaceutical industry.
\end{abstract}

\section{INTRODUCTION}

Nature has played an instrumental role in providing effective therapeutic entities. The historical relationship between mankind and the sea is usually for travelling, trading and as a nutritional source. Ocean cover more than $70 \%$ of the earth's surface but represents $95 \%$ of the biosphere (Ellis 2001). Chitin, found in the shell of crustaceans, the cuticles of insects, and the cell walls of fungi, is the second abundant biopolymer in the nature (Knorr 1984). Structurally, chitin is a straightchain polymer composed of $\beta-1$, 4-N-acetylglucosamine and

\footnotetext{
* Corresponding Author

E-mail: kprabu.cas@gmail.com

Telephone no: 01444-252099; Fax: 04144-243555
}

classified into $\alpha$-, $\beta$ - and $\gamma$-chitin (Cabib 1981; Cabib et al. 1988). Chitosan derived by partial $\mathrm{N}$-deacetylation of chitin is also a straight-chain polymer of glucosamine and $\mathrm{N}$-acetyl glucosamine (Muzzarelli et al. 1997). $\alpha$ - Chitin, the most abundant in nature, has a structure of antiparallel chains and is found in the crab, shrimp and lobster whereas $\beta$-chitin found in squid has intrasheet hydrogen bonding by parallel chains (Jang et al. 2004; Minke and Blackwell 1978). However, $\gamma$-chitin found in the cell walls of fungi has a mixture of parallel and antiparallel chains, which is a combination of $\alpha$-chitin and $\beta$-chitin (Jang et al. 2004). Because chitin and chitosan possesses many beneficially biological properties such as antimicrobial activity (Kobayashi et al. 1990; Tokoro et al. 1989), biocompatibility, biodegradability, haemostatic activity and wound 
healing property, much attention has been paid to its biomedical applications (Farkas 1990; Fleet and Phaff 1981). Due to these unique properties, chitosan and its derivatives have been proposed for applications in biomedical, food, agriculture, biotechnology and pharmaceutical fields (Felse and Panda 1999; Kumar 2000; Shahidi et al. 1999). Currently, the natural compounds are the focus of biotechnological companies looking for new antimicrobial agents (Tripathi and Dubey 2004).

Chitosan is a kind of fine biomaterial. Antimicrobial properties of chitosan and chitosan derivatives have been widely explored (Shahidi et al. 1999; Lim and Hudson 2003; Rabea et al. 2003). Antioxidant properties of chitosan derivatives have been studied (Lin and Chou 2004; Xie et al. 2001; Xing et al. 2005). Furthermore, antioxidant properties of fungal chitosan from shiitake stipes have also been studied (Yen et al. 2007).

However, antioxidant properties of chitosan derived from crab shells are not available. Accordingly, the objective of this study was to assess the antimicrobial and antioxidant properties of chitosan prepared from Podophthalmus vigil.

\section{MATERIALS AND METHODS}

\section{Collection of sample}

Shell materials were obtained from the wastes of Podophthalmus vigil were collected from Mudasal odai landing centre, south east coast of India.

Then packed in plastic bags and stored at $-20^{\circ} \mathrm{C}$ before and during transportation to the laboratory. Shells were scraped free of loose tissue from the crab wastes in laboratory, washed in double distilled water and dried at $60^{\circ} \mathrm{C}$. Standard chitin and chitosan obtained from Himedia, Mumbai. All other reagents were of analytical grade.

\section{Preparation of chitosan}

Chitin and chitosan were prepared from Podophthalmus vigil shell waste according to Takiguchi, 1991a and Takiguchi, $1991 b$.

\section{Isolation of chitin \\ Demineralization}

20 gm of sample powder was demineralised with $300 \mathrm{ml}$ of $2 \mathrm{~N} \mathrm{Hcl}$ for 24 hours with constant stirring and thus filtered. The filterate was again washed with distilled water and filtered till the liquid showed neutral PH. The filterate was then dried in a vacuum dryer and weighed.

\section{Deprotenization}

The sample was then deprotenized with $300 \mathrm{ml}$ of $1 \mathrm{~N}$ $\mathrm{NaOH}$ at $80^{\circ} \mathrm{C}$ for 24 hour with constant stirring. The $\mathrm{NaOH}$ was exchanged intermittently and the sample was washed with distilled water every time before adding fresh $\mathrm{NaOH}$. After 24 hour the sample was filtered. The sample filtrate was washed as before and dried. The weight was noted.

\section{Isolation of chitosan by Takiguchi, (1991b)}

The deprotenized sample was deacetylated with $250 \mathrm{ml}$ of $40 \% \mathrm{NaOH}$, treated for 6 hours at $110^{\circ} \mathrm{C}$ constant stirring. The sample was filtered and the filtrate was washed as before, $200 \mathrm{ml}$ of $10 \%$ acetic acid was added to the sample and stored for 12 hours at room temperature with constant stirring. The dissolving sample was reprecipated by adding $40 \% \mathrm{NaOH}$ to $\mathrm{P}^{\mathrm{H}} 10$. The sample was then disalysed by deionised water. It was then centrifuged at 10,000 rpm for 10 minutes and the precipitate was freeze dried.

\section{Preparation of stock solution}

Chitosan $(1.0 \mathrm{mg}$ ) was dissolved in $2 \mathrm{ml}$ of $1.0 \%$ (W/V) aqueous acetic acid solution. From this $0.25,0.50,0.75$ and $1.0 \mathrm{ml}$ was taken and made up to $1.0 \mathrm{ml}$ by adding $1 \%$ acetic acid to

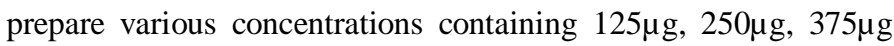
and $500 \mu \mathrm{g}$ of chitosan sample corresponding to $25,50,75$ and $100 \%$ respectively.

\section{Microbial strains used}

Antibacterial effect of chitosan was determined against 6 different bacterial strains viz., Salmonella typhii, Pseudomonas auergunosa, Staphylococcus aeureus, Escherichia coli, Klebsiella pneumonia and Bacillus substilis. Antifungal effect of chitosan was determined against 4 different fungal strains viz., Aspergillus flavus, Aspergillus fumigatus, Candida albicans, and Penicillium citrinum. These pathogenic strains were obtained from the department of Medical Microbiology (Raja Muthiah Medical College hospital) Annamalai University, Annamalai Nagar.

\section{Preparation of bacterial culture}

Nutrient broth medium was prepared and sterilized in an autoclave at $15 \mathrm{lbs}$ pressure. Nine bacterial species were incubated in the nutrient broth and incubated at $28 \pm 2{ }^{\circ} \mathrm{C}$ for 24 hours. Nutrient agar medium was also prepared, autoclave and transformed aseptically in to sterile Petri dishes. On this, 24 hours old bacterial broth cultures were inoculated by using a sterile cotton swab.

\section{Antibacterial Assay}

The antibacterial activity was studied using as test agent a range of 6 different strains of human pathogenic bacteria of which there were one antibiotic agent (tetracycline). In vitro antibacterial assay was carried out by disc diffusion technique (Bauer et al. 1966) in whatman No.1 filter paper discs with 4mm diameter were impregnated with known amount test samples. The disks were loaded each with $10 \mu \mathrm{l}$ of the extract by first applying 5 $\mu 1$ with the pipette, allowed to evaporate, then applying another 5 $\mu \mathrm{l}$, then drying again. The positive control contained of a standard antibiotic disc. Negative controls not comprised sterile disc only. The impregnated discs along with control (tetracycline) were kept at the center of agar plates, seeded with test bacterial cultures. The discs were then placed individually using a sterile forceps in 
appropriate grids which were marked on the undersurface of the plated Petri plates and kept for incubation at room temperature $\left(27^{\circ} \mathrm{C} \pm 2\right)$ for $24 \mathrm{~h}$. After incubation, plates were observed for zones of inhibition and recorded in millimeters.

\section{Preparation of fungal culture}

Stock cultures were maintained in Sabouraud Dextrose agar and 4 species of fungal pathogens was maintained in Sabouraud dextrose broth of 24 hours until used for antifungal activity.

$61.36 \mathrm{~g}$ of sabouraud dextrose agar powder suspended in $1000 \mathrm{ml}$ of distilled water and the $\mathrm{pH}$ was adjusted in $5.6 \pm 0.2$. The medium was boiled the dissolve completely and sterilized by autoclaving at $15 \mathrm{lbs}$ at $121 \mathrm{C}$ for 15 minutes. $50 \mathrm{~g}$ of Sabouraud dextrose broth powder suspended in $1000 \mathrm{ml}$ of distilled water and $\mathrm{pH}$ was adjusted in 5.6 \pm 0.2 . The medium was boiled the dissolve completely and sterilized by autoclaving at $15 \mathrm{lbs}$ at $121 \mathrm{C}$ for 15minutes.

\section{Antifungal Assay}

Stock cultures were maintained in sabouraud dextrose agar and 4 different species of fungal pathogen were maintained in Sabouraud Dextrose broth for 24 hours until used for antifungal activity. In vitro antifungal activity was determined by using the technique of (Bauer et al. 1966).

Six different species of fungal pathogen was inoculated by spread plate method using $0.1 \mathrm{ml}$ of 24hours old culture, maintained in Sabouraud Dextrose broth. Whatman No.1 filter paper $(4 \mathrm{~mm})$ discs impregnated with test samples of the chitosan. The discs were loaded each with $10 \mu \mathrm{l}$ of the extract by first applying $5 \mu \mathrm{l}$ with the pipette, allowed to evaporate, then applying another $5 \mu$, then drying again. The positive control (streptomycin) contained a standard antifungal disc. The inhibition zone was measured after 32 hours at $30 \mathrm{C}$ for the fungal plates. Antifungal activity was measured in term of diameter in term of diameter of zone (including the disc within) in $\mathrm{mm}$.

\section{Total antioxidant activity}

The antioxidant activity was determined by conjugated diene method (Lingnert et al. 1979). Each chitosan sample (0.1$10 \mathrm{mg} / \mathrm{ml}$ ) in $0.2 \%$ acetic acid solution was mixed with $2 \mathrm{ml}$ of $10 \mathrm{mM}$ linoleic acid emulsion $\left(\mathrm{P}^{\mathrm{H}} 6.5\right)$ in test tubes and placed in darkness at $37 \mathrm{C}$ to accelerate oxidation.

After incubation for 15 hour, $6 \mathrm{ml}$ of $60 \%$ methanol in deionised water was added, and the absorbance of the mixture was measured at $234 \mathrm{~nm}$ against blank in a Hitachi U-2001 UV-VIS spectrophotometer.

The antioxidant activity was calculated as follows:

Antioxidant activity $(\%)=[\Delta \mathrm{A} 234$ of control- $\triangle \mathrm{A} 234$ of sample) / $\triangle \mathrm{A} 234$ of control] X 100.

A control consisted of methanol and reagent solution without chitosan. An antioxidant activity value of $100 \%$ indicates the strongest antioxidant activity. Ascorbic acid, BHA and $\alpha$-tocopherol were used as a standard comparison.

\section{Reducing power}

Reducing power was determined according to the method of (Oyaizu 1986). Each chitosan sample $(0.1-10 \mathrm{mg} / \mathrm{ml})$ was mixed with $2.5 \mathrm{ml}$ of phosphate buffer $\left(0.2 \mathrm{M}, \mathrm{P}^{\mathrm{H}}-6.6\right)$ and $2.5 \mathrm{ml}$ of potassium ferric cyanide $(1 \%)$. Reaction mixture was kept in a water bath at $50^{\circ} \mathrm{C}$ for 20 minutes. After incubation, $2.5 \mathrm{ml}$ of trichloroacetic acid (10\%) was added and centrifuged at 3,000 rpm for 10 minutes. From the upper layer, $2.5 \mathrm{ml}$ solution was mixed with $2.5 \mathrm{ml}$ solution was mixed with $2.5 \mathrm{ml}$ of distilled water at $0.5 \mathrm{ml}$ of ferric chloride $(0.1 \%)$. Absorbance of all the solution was measured at $700 \mathrm{~nm}$. Increased absorbance indicated increased reducing power. Ascorbic acid and BHA were used for comparison.

\section{Chelating ability on ferrous ions}

Chelating ability was determined according to the method of (Dinis et al. 1994). Each chitosan sample $(0.1-10 \mathrm{mg} / \mathrm{ml}$, $1 \mathrm{ml}$ ) in $0.2 \%$ acetic acid solution was mixed with $3.7 \mathrm{ml}$ of methanol and $0.1 \mathrm{ml}$ of $2 \mathrm{mM}$ ferrous chloride. The reaction was initiated by the addition of $0.2 \mathrm{ml}$ of $5 \mathrm{mM}$ ferrozine. Then, the mixture was shaken vigorously and left at room temperature for 10 minutes. Absorbance of the mixture was determined at $562 \mathrm{~nm}$ against a blank. Citric acid and EDTA were used as standard. The inhibition percentage of ferrozine- $\mathrm{Fe}^{2+}$ complex formation was calculated by using the formula given below:

$$
\text { Metal chelating effect }(\%)=\left[\left(\mathrm{A}_{\text {Control }}-\mathrm{A}_{\text {Sample }}\right) / \mathrm{A}_{\text {Control }}\right] \times 100
$$

\section{Scavenging ability on 1, 1-diphenyl 1-2-picryl hydroxyl radicals (DPPH)}

The scavenging effect of chitosan on DPPH radical was examined using the modified method described earlier by (Shimada et al. 1992). Each chitosan sample $(0.1-10 \mathrm{mg} / \mathrm{ml})$ in $0.2 \%$ acetic acid solution was mixed with $1 \mathrm{ml}$ of methanolic solution containing DPPH radicals, results/resulted in a final concentration of $10 \mathrm{mM}$ DPPH. The mixture was shaken vigorously and left to stand for $30 \mathrm{~min}$ in the dark and the absorbance was then measured at $517 \mathrm{~nm}$ against a blank. Ascorbic acid, BHA and $\alpha$-tocopherol were used as standard. The scavenging ability was calculated as follows:

Scavenging ability $(\%)=[\Delta \mathrm{A} 517$ of control- $\triangle \mathrm{A} 517$ of sample) / $\triangle \mathrm{A} 517$ of control] X100.

\section{Hydroxyl radical assay}

The rate of reaction of hydroxyl radical with a putative antioxidant was determined by the deoxyribose method (Halliwell et al. 1987). The reaction mixture containing chitosan $(0.125,0.25$, $0.5,1.0,2.0 \mathrm{mg} / \mathrm{ml})$ was incubated with deoxyribose $(3.75 \mathrm{mM})$, $\mathrm{H}_{2} \mathrm{O}_{2}(1 \mathrm{mM}), \mathrm{FeCl}_{3}(100 \mathrm{lM})$, EDTA $(100 \mathrm{lM})$ and ascorbic acid $(100 \mathrm{lM})$ in potassium phosphate buffer $(20 \mathrm{mM}, \mathrm{pH} 7.4)$ for 60 $\mathrm{min}$ at $37 \mathrm{C}$. The reaction was terminated by adding $1 \mathrm{ml}$ of TBA $(1 \% \mathrm{w} / \mathrm{v})$ and $1 \mathrm{ml}$ of TCA (2\% w/v) and then heating the tubes for $15 \mathrm{~min}$ in a boiling water bath. After cooling, the absorbance of the mixture was measured at $535 \mathrm{~nm}$ against reagent blank. 
Ascorbic acid was used for comparison. The hydroxyl radical scavenging activity was calculated as following:

$$
\text { Scavenging effect }(\%)=\left[\left(\mathrm{A}_{\text {sample }}-\mathrm{A}_{\text {blank }}\right)\right] /\left[\left(\mathrm{A}_{\text {control }}-\mathrm{A}_{\text {blank }}\right)\right] \mathrm{X} 100
$$

Where $A_{\text {blank }}$ presents the absorbance of the blank (distilled water, instead of the chitosan) and $\mathrm{A}_{\text {control }}$ presents the absorbance of the control (distilled water, instead of $\mathrm{H}_{2} \mathrm{O}_{2}$ ). Each test replicated three times.

\section{Superoxide anion radical scavenging assay}

The superoxide scavenging ability of chitosan was assessed by the method of Xing. The reaction mixture, containing chitosan $(0.125,0.25,0.5,1.0,2.0 \mathrm{mg} / \mathrm{ml})$, PMS (30 lM), NADH (338 $\mathrm{lM})$ and NBT $(72 \mathrm{lM})$ in phosphate buffer $(0.1 \mathrm{M}, \mathrm{pH} 7.4)$, was incubated at room temperature for $5 \mathrm{~min}$ and the absorbance was read at $560 \mathrm{~nm}$ (Shimadzu UV-Vis Spectrophotometers) against a blank. Ascorbic acid was used for comparison. Each test replicated three times. The capability of scavenging to superoxide radical was calculated using the following equation:

Scavenging effect $(\%)=(1-\mathrm{A}$ sample $560 \mathrm{~nm} / \mathrm{A}$ control $560 \mathrm{~nm}) \mathrm{X}$ 100.

\section{RESULTS}

\section{Antimicrobial activity}

Antibacterial and antifungal activities of chitosan from Podophthalmus vigil screened against 6 human pathogenic bacterial strains and 5 fungal pathogens are presented in Table 1 $\& 2$.

Effect of chitosan on pathogenic bacteria revealed that, the highest activity $(13.04 \mathrm{~mm})$ was observed against Escherichia coli with highest (100\%) concentration. Regarding at 25, 50, 75\% concentration maximum activity $(12.04,11.09,11.06 \mathrm{~mm})$ was found against Escherichia coli. The lowest activity was found with $25 \%$ concentration against Bacillus substilis. Chitosan does not show inhibition against Pseudomonas auergunosa at all concentrations. At 25, 50, 75\% concentrations of chitosan does not show inhibition against Staphylococcus aeureus.

For fungi, the highest activity $(20.87 \mathrm{~mm})$ was observed against Penicillium citrinum with highest $(100 \%)$ concentrations. The lowest activity was found with $75 \%$ concentration against Aspergillus flavus. Chitosan does not show inhibition against Aspergillus fumigatus at all concentrations. At 25, 50\% concentrations of chitosan does not show inhibition against Staphylococcus aeureus.

\section{Total antioxidant activity}

In the conjugated diene method, the total antioxidant activity of chitosan was ranging from $18.37 \%$ to $79.58 \%$ at varying concentrations $(0.1$ to $10 \mathrm{mg} / \mathrm{ml})$. It showed consistent antioxidant activity with increased concentration whereas ascorbic acid and BHA reported $79.58 \%$ and $86.41 \%$ of antioxidant activity respectively at the highest concentration (Fig.1). Ascorbic acid and BHA were used as standard.

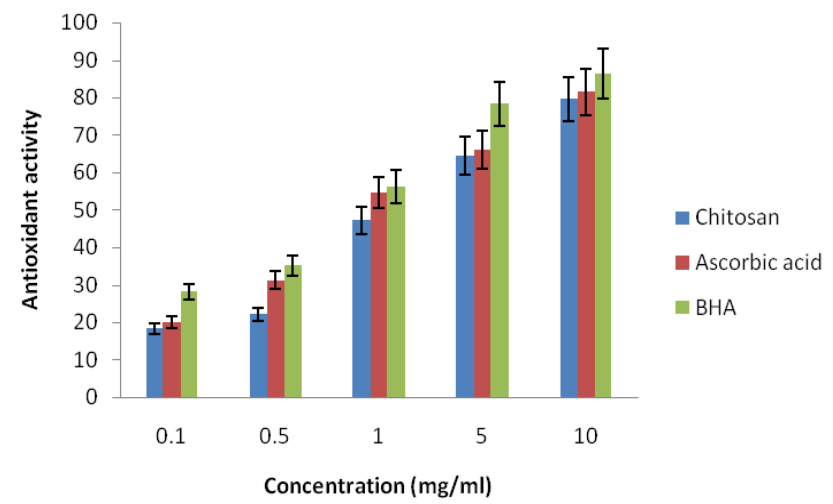

Fig. 1: Scavenging effects of the chitosan from Podophthalmus vigil, ascorbic acid and BHA on total antioxidant activity. Each test replicated three times. The bar represented \pm SD.

\section{Reducing power}

The reducing capability of chitosan from Podophthalmus vigil was assessed based on the measurement of $\mathrm{Fe}^{3+}-\mathrm{Fe}^{2+}$ transformation. At $0.1 \mathrm{mg} / \mathrm{ml}$ of chitosan showed slight reducing power of $0.12 \%$. The reducing power of chitosan was correlating well with increasing concentration. But values remained lower than, those for ascorbic acid and BHA $0.38 \%$ and $0.91 \%$ at $0.1 \mathrm{mg} / \mathrm{ml}$ respectively (Fig. 2). The reducing capability ranged from of $0.12 \%$ to $0.48 \%$ at varying concentration $(0.1$ to $10 \mathrm{mg} / \mathrm{ml})$. Ascorbic acid and BHA were used as standard.

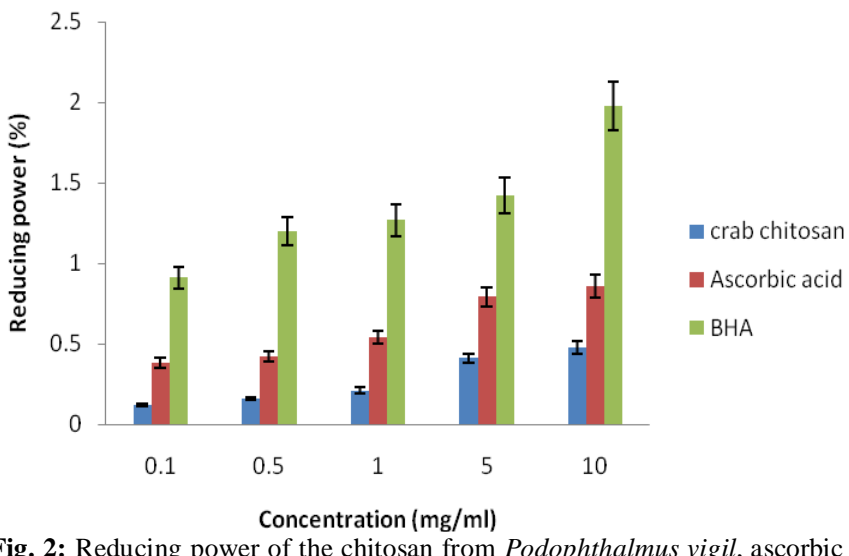
acid and BHA. Each test replicated three times. The bar represented \pm SD

\section{Scavenging ability on DPPH radicals}

The scavenging ability of chitosan from Podophthalmus vigil on DPPH radicals was reported at $55.56 \%$ at $10 \mathrm{mg} / \mathrm{ml}$. Ascorbic acid and BHA showed moderate to high scavenging abilities of $60.34 \%$ and $85.40 \%$ respectively. Thus the antioxidant activity of chitosan from Podophthalmus vigil was found to be a moderate scavenger for DPPH radicals. The DPPH radical scavenging potential of chitosan ranged from $18.08 \%$ to $55.56 \%$ at varying concentrations $(0.1$ to $10 \mathrm{mg} / \mathrm{ml})$. Ascorbic acid and BHA were used on standard (Fig. 3). 
Table. 1: Antibacterial Activity Of Chitosan

\begin{tabular}{|c|c|c|c|c|c|c|c|}
\hline \multirow{2}{*}{ Sl.No } & \multirow{2}{*}{ Microorganisms } & \multicolumn{6}{|c|}{ Concentration of chitosan } \\
\hline & & $500 \mu \mathrm{g}(100 \%)$ & $375 \mu \mathrm{g}(75 \%)$ & $250 \mu \mathrm{g}(50 \%)$ & $125 \mu \mathrm{g}(25 \%)$ & Positive control & Negative control \\
\hline 1. & Staphylococcus aeureus & $8.17 \pm 1.21$ & - & - & - & $20.07 \pm 1.21$ & - \\
\hline 2. & Salmonella typhi & $9.02 \pm 1.08$ & $8.10 \pm 1.19$ & $8.24 \pm 0.27$ & $8.07 \pm 1.15$ & $17.03 \pm 0.84$ & - \\
\hline 3. & Escherichia coli & $13.04 \pm 1.11$ & $12.04 \pm 0.35$ & $11.09 \pm 0.43$ & $11.06 \pm 0.32$ & $18.04 \pm 0.12$ & - \\
\hline 4. & Klebsiella pneumoniae & $10.07 \pm 0.06$ & $9.07 \pm 1.16$ & $8.07 \pm 1.20$ & $8.11 \pm 0.64$ & $18.15 \pm 1.08$ & - \\
\hline 5. & Pseudomonas auergunosa & - & - & - & - & $16.09 \pm 0.53$ & - \\
\hline 6. & Bacillus substilis & $9.17 \pm 1.17$ & $8.12 \pm 0.36$ & $8.18 \pm 0.28$ & $8.01 \pm 0.86$ & $13.07 \pm 1.17$ & - \\
\hline
\end{tabular}

$(-)=$ No zone of inhibition

Results indicates zone of inhibition in $\mathrm{mm}$ indicate the distance from the border of the disc to the edge of the clear zone.

Values are given as mean \pm SD of three experiments.

Positive control (Tetracycline100 $\mu \mathrm{g}$ ); Negative Control (Sterile Disc)

Table. 2: Antifungal Activity of Chitosan

\begin{tabular}{|c|c|c|c|c|c|c|c|}
\hline \multirow[b]{2}{*}{ Sl.No } & \multirow[b]{2}{*}{ Microorganisms } & \multicolumn{6}{|c|}{ Concentration of chitosan } \\
\hline & & $500 \mu \mathrm{g}(100 \%)$ & $375 \mu \mathrm{g}(75 \%)$ & $250 \mu \mathrm{g}(50 \%)$ & $125 \mu \mathrm{g}(25 \%)$ & Positive control & $\begin{array}{c}\text { Negative } \\
\text { control }\end{array}$ \\
\hline 1. & Aspergillus flavus & $4.43 \pm 0.87$ & $2.38 \pm 0.65$ & - & - & $16.17 \pm 0.53$ & - \\
\hline 2. & Candida albicans & $10.64 \pm 0.29$ & $9.27 \pm 0.44$ & $8.39 \pm 0.47$ & $8.77 \pm 1.12$ & $12.08 \pm 0.73$ & - \\
\hline 3. & Aspergillus fumigatus & - & - & - & - & $11.27 \pm 0.49$ & - \\
\hline 4. & Penicillium citrinum & $20.87 \pm 0.59$ & $18.17 \pm 0.84$ & $12.56 \pm 1.25$ & $10.07 \pm 0.67$ & $15.47 \pm 1.18$ & - \\
\hline
\end{tabular}

$(-)=$ No zone of inhibition

Results indicates zone of inhibition in mm indicate the distance from the border of the disc to the edge of the clear zone.

Values are given as mean \pm SD of three experiments.

Positive control (Streptomycin-100 $\mu \mathrm{g}$ )

Negative Control (Sterile Disc)

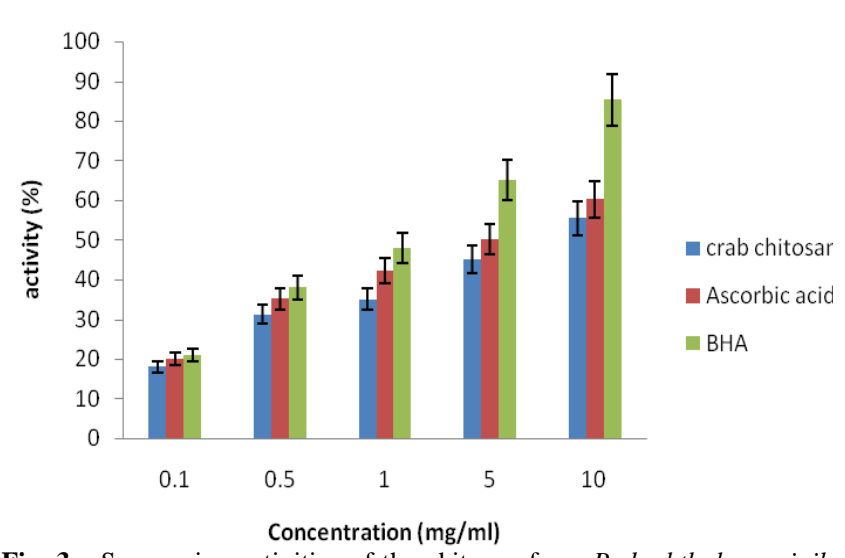

Fig. 3: Scavenging activities of the chitosan from Podophthalmus vigil, ascorbic acid and BHA on DPPH radical. Each test replicated three times. The bar represented \pm SD.

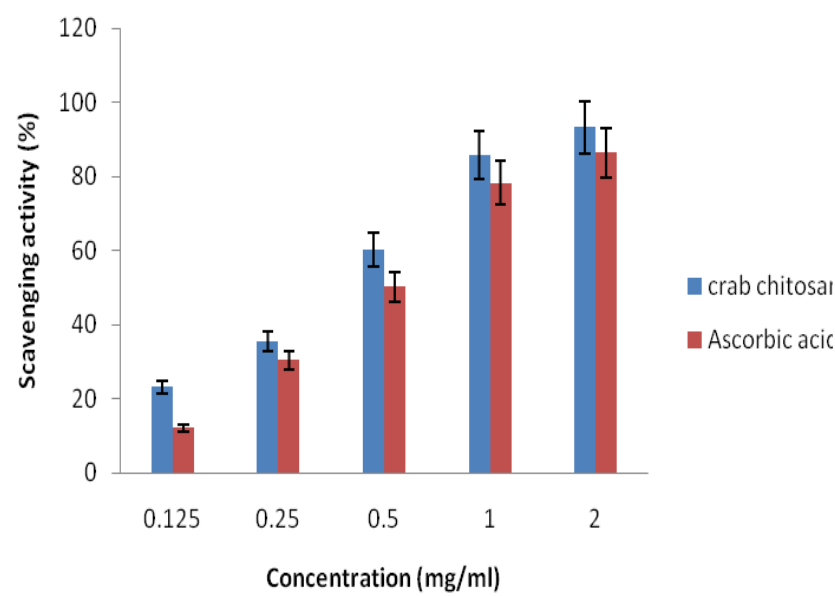

Fig. 5: Scavenging effects of the chitosan from Podophthalmus vigil and ascorbic acid on hydroxyl radicals. Each test replicated three times. The bar represented $\pm \mathrm{SD}$.

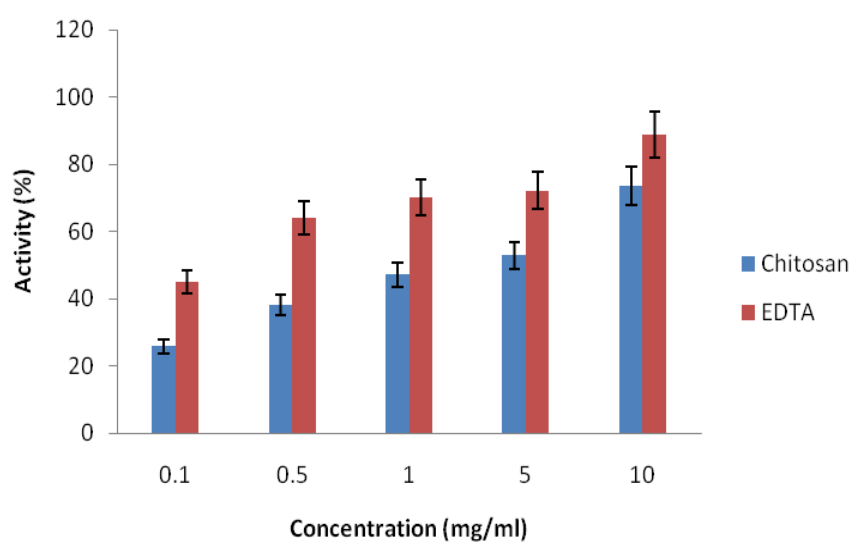

Fig. 4: Ferrous ions chelating ability of the chitosan from Podophthalmus vigil and EDTA. Each test replicated three times. The bar represented \pm SD.

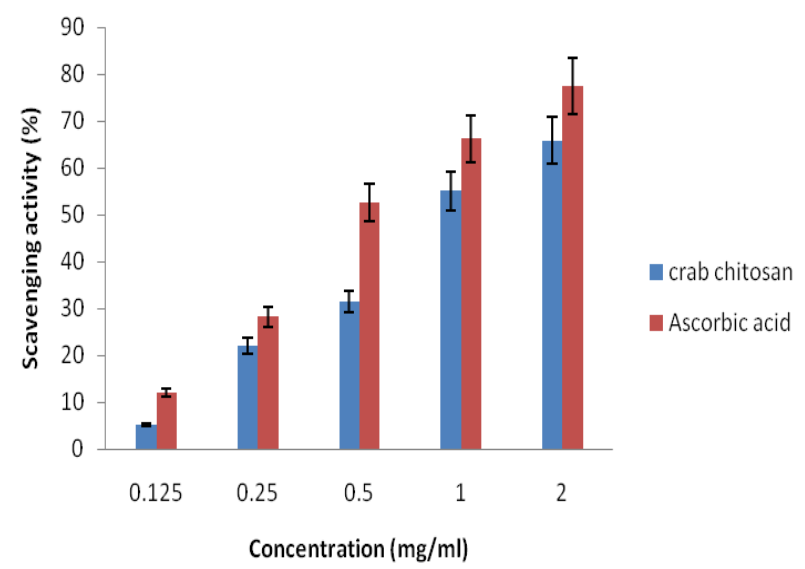

Fig. 6: Scavenging effects of the chitosan from Podophthalmus vigil and ascorbic acid on Superoxide anion radicals. Each test replicated three times. The bar represented $\pm \mathrm{SD}$ 


\section{Chelating effect on ferrous ions}

The chelating ability of chitosan form Podophthalmus vigil on ferrous ions was ranging from $25.82 \%$ to $73.54 \%$ for the concentration between $0.1-10 \mathrm{mg} / \mathrm{ml}$ (Fig. 4). However, the chelating effect of EDTA $(0.1-10 \mathrm{mg} / \mathrm{ml})$ was found to be higher than the chitosan and the range was from $45.12 \%$ to $88.75 \%$. EDTA was used as standard.

\section{Hydroxyl radical scavenging activity}

The chitosan from the shell of Podophthalmus vigil had obvious scavenging activity and exhibited a stronger concentration-dependent inhibition of deoxyribose oxidation. Moreover, it had stronger Scavenging activity on hydroxyl radical than ascorbic acid (Fig. 5). Scavenging effect of chitosan was $60.25 \%$ at concentration of $0.5 \mathrm{mg} / \mathrm{ml}$, whereas scavenging effect of ascorbic acid was $50.15 \%$ at same concentration. Hydroxyl radicals scavenging activity of chitosan $(0.125-2 \mathrm{mg} / \mathrm{ml})$ was found to be higher than the ascorbic acid and the range was from $23.18 \%$ to $93.28 \%$. Ascorbic acid was used as standard.

\section{Superoxide anion radical scavenging activity}

The inhibitory effect of the chitosan from the shell of Podophthalmus vigil on superoxide anion radical was ranging from $5.21 \%$ to $65.81 \%$ for the concentration between $0.125-2$ $\mathrm{mg} / \mathrm{ml}$ (Fig. 6). However, the scavenging effect of Ascorbic acid $(0.125-2 \mathrm{mg} / \mathrm{ml})$ was found to be higher than the chitosan and the range was from $12.12 \%$ to $77.41 \%$. Ascorbic acid was used as standard.

\section{DISCUSSION}

As a kind of macromolecule polymer, Chitosan seems to be unable to pass the outer membrane of bacteria, since this membrane functions as an efficient outer permeability barrier against macromolecules. Therefore, direct access to the intracellular parts of the cells by Chitosan is unlikely. The antibacterial mechanisms of Chitosan suggested being, the positive charge of the amino group at $\mathrm{C}-2$ resulted in a polycationic structure which can be expected to interact with the predominantly anionic components (lipopolysaccharides, proteins) of the microorganisms surface (Helander et al. 2002). The interaction resulted in great alteration of the structure of outer membrane (Helander et al. 1998), which caused release of major proportion of proteinaceous material from the cells (Vaara and Vaara 1983). As a result, the chitosan was easier to interact with anionic components of cell surface, and exhibited higher inhibitory activities. According to literature (Jeon et al. 2001; Ueno et al. 1997), chitosan possesses antimicrobial activity against a number of Gram-negative and Gram-positive bacteria. This study has been conducted to assess inhibitory effects of chitosan. The effectiveness of chitosan bacteriastatic properties were tested against bacterial strains.

Yen et al. (2008) reported that crab chitosan showed moderate to high antioxidant activities of $58.3-70.2 \%$ at $1 \mathrm{mg} / \mathrm{ml}$ and high antioxidant activities of $79.9-85.2 \%$ at $10 \mathrm{mg} / \mathrm{ml}$. In addition, the antioxidant activities of crab chitosan C60, C90 and C120 correlated with their N-deacetylation times. In the present investigation, chitosan showed consistent antioxidant activity with increased concentration. Antioxidant activity of chitosan from Podophthalmus vigil was $18.37-79.58 \%$ at 0.1 to $10 \mathrm{mg} / \mathrm{ml}$, shown lesser than that of both the fungal and crab chitosan which may due to the differences in $\mathrm{N}$-deacetylation times.

One important mechanism of antioxidant involves the scavenging of hydrogen radicals. DPPH has a hydrogen free radical and shows a characteristic absorption at $517 \mathrm{~nm}$ (BrandWilliams et al. 1995). After encountering the proton-radical scavengers, the purple color of the DPPH solution fades rapidly (Yamaguchi et al. 1998). In this study, DPPH was used to determine the proton-scavenging activity of the various disaccharide chitosan derivatives.

Yen et al. (2008) reported that fungal chitosan scavenged DPPH radicals by $28.4-53.5 \%$ at $10 \mathrm{mg} / \mathrm{ml}$, obviously chitosan from crab shells and shiitake stipes was also not an effective scavenger for DPPH radicals. Yen et al. (2007) reported the scavenging ability of crab chitosan C60 on DPPH radicals was $28.4 \%$ at $10 \mathrm{mg} / \mathrm{ml}$, whereas these of other crab chitosan were in the range of 46.4-52.3\%. The scavenging ability of chitosan from Podophthalmus vigil was $55.56 \%$ at $10 \mathrm{mg} / \mathrm{ml}$. However, at $10 \mathrm{mg} / \mathrm{ml}$, BHA and Ascorbic acid showed scavenging abilities of $85.40 \%$ and $60.34 \%$ respectively.

The reducing power of different molecular weights of $\gamma$ ray treated chitosan has determined by potassium ferricyanide reduction method showed that low molecular weight $\gamma$-ray treated chitosan exhibited high reducing power and the reducing power increased with the increases of chitosan concentration (Feng et al. 2008). In the present study, the reducing power of chitosan from Podophthalmus vigil was 0.48 at $10 \mathrm{mg} / \mathrm{ml}$. However, BHA and ascorbic acid showed reducing power of 1.98 and 0.86 at $10 \mathrm{mg} / \mathrm{ml}$ respectively. It shows that chitosan from Podophthalmus vigil was not effective in reducing power. It seems that reducing powers of chitosan also correlated with their $\mathrm{N}$-deacetylation times (Yen $e t$ al. 2007).

The $\mathrm{Fe}^{2+}$ chelating ability of chitosan mainly comes from the presence of amino groups, which contain lone pairs that help to form chitosan- $\mathrm{Fe}_{2}{ }^{+}$complexes (Guzman et al. 2003). And $\mathrm{Fe}_{2}{ }^{+}$ chelating ability of low molecular weight chitosan was more pronounced than high molecular weight chitosan (Xing et al. 2005b).

Huang et al. (2005) added EDTA to the reaction system to release the $\mathrm{Fe}^{2+}$ that had become chelated by the chitosan, and the scavenging activity against hydroxyl radical decreased. EDTA is a more effective chelate for $\mathrm{Fe}^{2+}$ than chitosan, and so released $\mathrm{Fe}^{2+}$ can react with $\mathrm{H}_{2} \mathrm{O}_{2}$ to generate excessive amounts of hydroxyl radicals, which result in the decrease of radical scavenging activity. Therefore, $\mathrm{Fe}^{2+}$ chelating directly correlate to the scavenging behavior of chitosan.

In the present investigation, the chelating ability of chitosan from Podophthalmus vigil on ferrous ion was $73.54 \%$ at 
$10 \mathrm{mg} / \mathrm{ml}$ and $25.82 \%$ at $0.1 \mathrm{mg} / \mathrm{ml}$ respectively. The chelating abilities of chitosan correlated with their N-deacetylation times. However, EDTA showed high chelating ability of $88.75 \%$ at $10 \mathrm{mg} / \mathrm{ml}$. Yen et al. (2007) reported that $1 \mathrm{mg} / \mathrm{ml}$ chelating abilities of fungal chitosan were all chelated. Lin and Chou (2004) reported that the chelating abilities of $\mathrm{N}$-alkylated disaccharide chitosan derivative were less than that observed with EDTA.

Superoxide anion is a reduced form of molecular oxygen created by receiving one electron. It is an initial free radical formed from mitochondrial electron transport system (Bloknina et al. 2003). Superoxide anion radicals are produced by a number of cellular reactions, including various enzyme systems, such as lipoxygeneases, peroxidase, NADPH oxidase and xanthine oxidase. They play an important role in the formation of other cell damaging free radicals, such as hydrogen peroxide, hydroxyl radical, or singlet oxygen in living systems. In the present study a superoxide radical scavenging assay was based on the capacity of chitosan to inhibit the reduction of nitro blue tetrazolium (NBT).

Significant scavenging of superoxide radical was evident at all the tested concentration of chitosan. At $0.5 \mathrm{mg} / \mathrm{ml}$, the scavenging percentage of chitosan from Podophthalmus vigil against superoxide radical was $31.47 \%$.

Although superoxide is a relatively weak oxidant, it decomposes to form stronger reactive oxidative species, such as single oxygen and hydroxyl radicals, which initiate peroxidation of lipids (Dahl and Richardson 1978). In the present study, chitosan effectively scavenged superoxide in a concentration dependent manner. Further, superoxides are also known to indirectly initiate lipid peroxidation as a result of $\mathrm{H}_{2} \mathrm{O}_{2}$. Hydroxyl radical scavenging activity of chitosan was obtained in the deoxyribose system. In this system, chitosan exhibited a concentration-dependent inhibition of deoxyribose oxidation. Earlier, numerous workers (Halliwell et al. 1987) have employed this system to assess the biological activity of various natural plant-derived biomolecules. Smith et al. (1992) reported that molecules that can inhibit deoxyribose degradation are those that can chelate iron ions and render them inactive or poorly active in a Fenton reaction. In the present study, in another assay system, we found chitosan had moderate chelating effect. So, it is likely that the chelating effect of chitosan on metal ions may not be responsible for the inhibition of deoxyribose oxidation.

\section{CONCLUSION}

Based on this study, Chitosan show significant antimicrobial and antioxidant activity. The antimicrobial activity of chitosan in different concentration was studied. The effect of chitosan against human pathogens can be successfully determined by the agar disc diffusion assay. According to our results, as the concentration of chitosan increased, the antimicrobial effect was strengthened. Antioxidative properties of the various chitin and chitosan extracts are of great interest in food industry, since their possible use as natural additives emerged from a growing tendency to replace synthetic antioxidants by natural ones. Owing to its excellent protective features exhibited in antioxidant activity tests, the chitin and chitosan extracts from the crustacean species could be concluded as a natural source that can be freely used in the food industry. This study identifies opportunities to develop value added products from crustacean processing by-products with different biological activity such as antioxidant, antibacterial and antifungal properties.

\section{ACKNOWLEDGEMENT}

The authors are thankful to Prof. T. Balasubramanian, Dean, CAS in Marine Biology, Annamalai University, Parangipettai for the facilities provided in carrying out this work.

\section{REFERENCES}

Bauer AW, Kirby WM, Cherris JC, and Truck M. Antibiotic susceptibility testing by a standardized single disk method. The American Journal of Clinical Pathology. 1966; 45, No 4, 493-496.

Bloknina O, Virolainen E, and Fagerstedt KV. Antioxidants, oxidative damage and oxygen deprivation stress: A review. Annals of Botany. 2003; 91, 179-194.

Brand-Williams W, Cuvelier ME, and Berset C. Use of a free radical method to evaluate antioxidant activity, Food Science and Technology. 1995; 28: 25-30.

Cabib E, Bowers B, Sburlati A, and Silverman SJ. Fungal cell wall synthesis: The construction of a biological structure. Microbiological Science. 1988; 5, 370-375.

Cabib E. Chitin: Structure, metabolism and regulation of biosynthesis. Encyclopedia of Plant Physiology New Series. 1981; 13B, 395-415.

Dahl MK, and Richardson T. Photogeneration of superoxide anion in serum of bovine milk and in model systems containing riboflavin and amino acid. Journal of Dairy Science. 1978; 61, 400-407.

Dinis TCP, Madeira VMC, and Almeida, LM. Action of phenolic derivates (acetoaminophen, salycilate, and 5-aminosalycilate) as inhibitors of membrane lipid peroxidation and as peroxyl radical scavengers. Arch. Biochem. Biophys. 1994; 315: 161-169.

Ellis R. The origin and evolution of life in the sea. Aquagenesis. 2001; Viking Eds. New York.

Farkas V. Fungal cell walls: Their structure, biosynthesis and biotechnological aspects. Acta Biotechnologica. 1990; 10, 225-238.

Felse PA, and Panda T. Studies on applications of chitin and its derivatives. Bioprocess Engineering. 1999; 20, 505-512.

Feng T, Du Y, Li J, and Kennedy JF. Enhancement of antioxidant activity of chitosan by irradiation. Carbohydr Polym. 2008; 73, 126-132.

Fleet GH, and Phaff HJ. Fungal glucans-structure and metabolism. Encyclopedia of Plant Physiology New Series. 1981; 13B, 416-440.

Guzman J, Saucedo I, Revilla J, Navarro R, and Guibal E. Copper sorption by chitosan in the presence of citrate ions: influence of metal speciation on sorption mechanism and uptake capacities. International Journal of Biological Macromolecules. 2003; 33, 57-65.

Halliwell B, Gutteridge JM, and Aruoma OI. The deoxyribose method: a simple "test-tube" assay for determination of rate constants for reactions of hydroxyl radicals. Analytical Biochemistry. 1987; 165, 215219

Helander IM, Latva-Kala K, and Lounatmaa K. Permeabilizing action of polyethyleneimine on Salmonella typhimurium involves disruption of the outer membrane and interactions with lipopolysaccharide. Microbiology. 1998; 144, 385-390.

Helander IM, Nurmiaho-Lassila EL, Ahvenainen R, Rhoades J, and Roller S. Chitosan disrupts the barrier properties of the outer membrane of Gram-negative bacteria. International Journal of Food Microbiology. 2002; 71, 235-244. 
Huang M, Fong CW, and Khor E. Transfection efficiency of chitosan vectors: Effect of polymer molecular weight and degree of deacetylation. J Control Release. 2005; 106:391-406.

Jang MK, Kong BG, Jeong YI, Lee $\mathrm{CH}$, and Nah JW. Physicochemical characterization of $\alpha$-chitin, $\beta$-chitin and $\gamma$-chitin separated from natural resources. Journal of Polymer Science, Part A: Polymer Chemistry. 2004; 42, 3423-3432.

Jeon YJ, Park PJ, and Kim SK. Antimicrobial effect of chitooligosaccharides produced by bioreactor. Carbohydrate Polymers. $2001 ; 44,71-76$.

Knorr D. Use of chitinous polymers in food - A challenge for good research and development. Food Technology. 1984; 38(1), 85-89, 92-97.

Kobayashi M, Watanabe T, Suzuki S, and Suzuki M. Effect of $\mathrm{N}$-acetylchitohexaose against Candida albicans infection of tumor-bearing mice. Microbiology and Immunology. 1990; 34, 413-426.

Kumar MNVR. A review of chitin and chitosan applications. Reactive and Functional Polymers. 2000; 46, 1-27.

Lim SH, and Hudson SM. Review of chitosan and its derivatives as antimicrobial agents and their uses as textile chemicals. Journal of Macromolecular Science. Part C-Polymer Reviews. 2003; C43, 223-269.

Lin HY, and Chou CC. Antioxidant activities of water-soluble disaccharide chitosan derivatives. Food Research International. 2004; 37, 883-889.

Lingnert $\mathrm{H}$, Vallentin $\mathrm{K}$, and Eriksson CE. Measurement of antioxidative effect in model system. J. Food Prot. Presv. 1979; 3: 87103.

Minke R, and Blackwell J. The structure of $\alpha$-chitin. Journal of Molecular Biology. 1978; 120, 167-172.

Muzzarelli RAA, Rochetti R, Stanic V, and Weckx M. Methods for the determination of the degree of acetylation of chitin and chitosan. In Muzzarelli RAA, and Peter MG (Eds.), Chitin handbook. 1997; 109-119.

Oyaizu M. Studies on products of browning reactions: Antioxidative activities of products of browning reaction prepared from glucosamine. Japn. J. Nutr. 1986; 44: 307-315.

Rabea EI, Badawy MET, Stevens CV, Smagge G, and Steurbaut W. Chitosan as antimicrobial agent: Application and mode of action. Biomacromolecules. 2003; 4, 1457-1465.

Shahidi F, Arachchi JKV, and Jeon YJ. Food applications of chitin and chitosan. Trends in Food Science and Technology. 1999; 10, $37-51$.

Shimada K, Fujikawa K, Yahara K, and Nakamura T. Antioxidative properties of xanthan on the autoxidation of soybean oil in cyclodextrin emulsion. J. Agric. 1992; 40: 945-948.

Smith C, Halliwell B, and Aroma OI. Protection by albumin against the pro-oxidant actions of phenolic dietary components. Food Chem. Toxicol. 1992; 6: 483-489.
Takiguchi Y. Physical properties of chitinous materials. In: R.H. Chen and H.C. Chen (eds.), Advances in Chitin Science, Vol. III Proceedings from the third Asia - Pacific Chitin, Chitosan Jikken manual chapter 1, Gihodou Shupan Kabushki Kaisha, Japan, 1991a; 1- 7.

Takiguchi Y. Preparation of chitosan and partially deacetylated chitin. In: A. Otakara and M. Yabuki (eds.), Chitin, Chitosan Jikken Manual Chapter-2, Gihodou Shupan Kaisha, Japan. 1991b; 9-17.

Tokoro A, Kobayashi M, Tatewaki N, Suzuki K, Okawa Y, and Mikami T. Protective effect of N-acetylchitohexaose on Listeria monocytogenes infection in mice. Microbiology and Immunology. 1989; $33,357-367$

Tripathi P, and Dubey NK. Postharvest Biol. Technol. 2004; 32 $235-245$.

Ueno K, Yamaguchi T, Sakairi N, Nishi N, and Tokura S. Antimicrobial activity by fractionated chitosan oligomers. In: Domard, A., Roberts, G.A.F. and Varum, K.M., Editors. Jacques Andre, Lyon, Adv. chitin Sci. 1997; 2 : 156-161.

Vaara M, and Vaara T. Polycations as outer membrane disorganizing agents. Antimicrobiology Agents Chemotherapeutant. 1983; 24, 114-122.

Xie W, Xu P, and Liu Q. Antioxidant activity of water-soluble chitosan derivatives. Bioorganic and Medicinal Chemistry Letters. 2001; 11, 1699-1701.

Xing R, Yu H, Liu S, Zhang W, Zhang Q, and Li Z. Antioxidant activity of differently regioselective chitosan sulfates in vitro. Bioorganic and Medical Chemistry. 2005b; 13, 1387-1392.

Xing $\mathrm{R}$, Yu H, Liu S, Zhang $\mathrm{W}$, Zhang $\mathrm{Q}$, and Li Z. Antioxidative activity of differently regioselective chitosan sulfates in vitro. Bioorganic and Medicinal Chemistry. 2005a; 13, 1387-1392.

Yamaguchi $\mathrm{T}$, Takamura $\mathrm{H}$, Matoba $\mathrm{T}$, and Terao J. HPLC method for evaluation of the free radical-scavenging activity of foods by using 1,1-diphenyl-2-picrylhydrazyl. Biosci Biotechnol Biochem. 1998; 62: 1201-1204.

Yen M, Yang J, and Mau J. Antioxidant properties of chitosan from crab shells. Carbohydrate Polymers. 2008; 74, 840-844.

Yen MT, Tseng YH, Li RC, and Mau JL. Antioxidant properties of fungal chitosan from shiitake stipes. LWT - Food Science and Technology. 2007; 40, 255-261.

Yen MT, Tseng YH, Li RC, and Mau JL. Antioxidant properties of fungal chitosan from shiitake stipes. LWT-Food Science and Technology. 2007; 40, 255-261.

\section{How to cite this article:}

K. Prabu and E. Natarajan. In Vitro Antimicrobial and Antioxidant Activity of Chitosan Isolated from Podophthalmus Vigil. J App Pharm Sci. 2012; 2(9): 075-082. 